\title{
Research Paper: Presenting a Model for Telemedicine in Earthquake for Iran
}

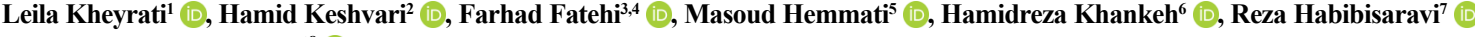 \\ , Mohammadreza Kheyrati ${ }^{8}$ [D
}

1. Manager of Medical Care Monitoring Center (MCMC), Ministry of health and Medical Education, Tehran, Iran.

2. Faculty of Medical Engineering, Amirkabir University, Tehran, Iran.

3. Center for Online Health, The University of Queensland, Brisbane, Australia.

4. Adjunct Fellow, Tehran University of Medical Sciences, Tehran, Iran.

5. Head of Information Technology Center, Islamic Azad University, Tehran, Iran.

6. Postdoc Fellow, University of Social Welfare and Rehabilitation Sciences, Tehran, Iran.

7. Information and Communication Technology Administration, Mazandaran University of Medical Sciences, Sari, Iran.

8. Information Technology Management, Information Technology Center, Islamic Azad University, Tehran, Iran.

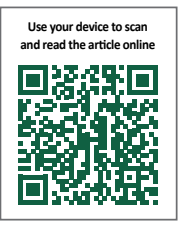

Citation: Kheyrati L, Keshvari H, Fatehi F, Hemmati M, Khankeh H, Habibisaravi R, et al. Presenting a Model for Telemedicine in Earthquake for Iran. Health in Emergencies and Disasters Quarterly. 2019; 4(3):157-164. http://dx.doi.org/10.32598/hdq.4.3.157

: http://dx.doi.org/10.32598/hdq.4.3.157

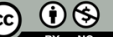

Article info:

Received: 22 Oct 2018

Accepted: 13 Feb 2019

Available Online: 01 Apr 2019

\section{Keywords:}

Telemedicine, Disasters, Emergency, Earthquake, Iran

\section{ABSTRACT}

Background: Iran is a country with a high rate of natural disasters like earthquake. The environmental conditions slow down the delivery of health services, especially in the event of disasters. The modern technologies such as telemedicine are appropriate for facilitating disaster relief operations after an earthquake. This study aimed to develop a model for the implementation of telemedicine in an earthquake.

Materials and Methods: The study was carried out using a mixed-methods research in three phases: 1. Review of the literature; 2. Qualitative study (modeling); and 3. Delphi method (validation of the model). Databases of Google Scholar, Web of Science, Scopus, and PubMed were searched from 1990 to 2019 with the keywords of "telemedicine" AND "disaster" OR "emergency" AND "earthquake". After screening of the retrieved records, 13 articles met the eligibility criteria and were included in the review study. Ten experts extracted all key elements of telemedicine in the disaster from the articles and categorized them in 6 themes with 38 subthemes. The model of telemedicine in the earthquake was finalized with 2 rounds of Delphi with groups of selected volunteer experts.

Results: In the first phase of the study, 6 key themes (telecommunication infrastructure, technical infrastructure, financial infrastructure, health infrastructure, organizational infrastructure, social infrastructure, and cultural infrastructure) with 38 subthemes of telemedicine for implementing in the disaster were obtained. At the conclusion of the third phase of the study, 6 key themes with 33 subthemes contributed to the model of telemedicine in the earthquake. Telecommunication infrastructure with a maximum score of 9.24 earned the priority, and social and cultural infrastructure themes with the minimum score of 7.53 came in the end.

Conclusion: The model derived from this study can be used as an applied telemedicine model in an earthquake. We suggest that the results of this study be implemented as a theoretical model, or in a pilot study in a region of the country, and to be evaluated by regarding mortality reduction. We also recommend that a comparative study for using telemedicine in other types of disasters be undertaken.

\section{* Corresponding Author:}

Hamid Keshvari, PhD.

Address: Faculty of Medical Engineering, Amirkabir University, Tehran, Iran

E-mail: hamid.keshvari@yahoo.com 


\section{Introduction}

$\mathrm{n}$ recent decades, longer life expectancy resulted in an increasing demand for health care. The use of Information and Communication Technology (ICT) is a way to expand health services to these growing needs [1]. ICT has various applications in health services in many fields. The health information network, remote medical networks, and patient's electronic records are examples of health information technology applications [2].

Telemedicine, as a new technology in the 21 st century, is one of the latest ICT technologies that can be used for delivering health services remotely [3] . High-speed telecommunications systems and the invention of devices capable of capturing and transmitting images in digital form had main roles in development [4] . Not only using proper hardware and software is essential, but we also need expert users [5]. There are four factors for prospering telemedicine: therapists' motivation, proper infrastructure, ongoing investment, and technical support [6].

Providing health services in disasters is one of the essential applications of telemedicine. In the event of disasters, local health facilities can be severely damaged- local hospitals and clinics may be physically damaged or inaccessible. In this situation, various telemedicine services could be applicable. Distance counseling, distance education, remote monitoring, and remote operation, as well as various types of data transmission (text, audio, image, etc.), are among these services [7]. The implementation of the telemedicine system can be effective in solving health problems in affected areas, especially during the early hours of the disaster.

The National Aeronautics and Space Administration (NASA) was the first organization that used telecommunication technology in the Mexico City earthquake in 1985. The disaster managers and rescue and relief personnel communicate with each other by satellite voice communication [8].

So many disasters occurred in Iran previously and placed it among the top 10 countries with disaster occurrence in the world. Seismic activity is the most frequent hazard in Iran, and several major faults cross most area of the country [9].

Iran has special environmental and geographical conditions as well. There are many mountainous and desert areas in Iran [10]. In these conditions, we need new tech- nologies to meet the health requirements of the disasteraffected population. Given the special circumstances of Iran, telemedicine can be considered as one of the ways to provide health services in disasters. The present study was designed to provide a practical model for telemedicine implementation in disasters in Iran, especially in earthquakes.

\section{Materials and methods:}

According to the research objectives, the present study was carried out using a mixed-methods research in three phases: a review of articles, qualitative study (modeling), and Delphi method (validation of model).

In the first phase, available articles were reviewed to determine the factors affecting the successful deployment of telemedicine in disaster. All databases such as Google Scholar, Web of Science, Scopus were searched from 1990 to the end of 2017 with the keywords of "telemedicine" And "disaster" Or "emergency" And "earthquake". The inclusion criteria were articles in English or Farsi published up to 2019, about telemedicine, disaster, or emergency and earthquake. According to title and abstract, of 3024 articles, all irrelevant documents ruled out. After reading the content of 76 remaining articles, 13 articles with full text remained for further analysis (Table 1). All key themes of telemedicine in the disaster were extracted from articles. With the discussion in the expert panel of 10 selected professionals, all elements were categorized as 6 key themes with 38 subthemes. The participants gave a score to all items from 1 to 5 . Mean, median, mode, and standard deviation values of each item were calculated. Finally, themes and subthemes were ranked by mean scores.

In the second phase, a group of 35 selected volunteer experts (Table 2) enrolled in Delphi to finalize the initial framework. A researcher-made questionnaire was used for data collection, which was validated by face validity, and its reliability was positively evaluated by the Cochran's formula with the Cronbach alpha coefficient of 0.911 . The participants scored each item from 1 to 10 for the final scoring and ranking. At the end of this phase, the applicable model of telemedicine in the disaster was determined.

Subsequently, in the third phase, the second round of Delphi with 29 remaining experts performed to finalize modeling of telemedicine in disasters with the focus on the earthquake. SPSS V. 18 was used for doing statistical analyses and preparing descriptive results. 
Table 1. Articles used in the review

\begin{tabular}{|c|c|c|c|}
\hline No. & Author(s) & Title & Year \\
\hline 1 & Bashshur et al. [1] & Telemedicine: Theory and Practice & 1997 \\
\hline 2 & $\begin{array}{l}\text { Crane, Wiegand, Kamali, Reif, Wratni, Montante } \\
\qquad \text { R, et al. [2] }\end{array}$ & $\begin{array}{c}\text { Telemedicine Delivery and Successful Reimbursement in Toxicol- } \\
\text { ogy }\end{array}$ & 2018 \\
\hline 3 & Nicogossian \& Doarn. [3] & $\begin{array}{l}1988 \text { Armenia Earthquake and Telemedicine: Lessons Learned and } \\
\text { Forgotten, Telemedicine and e-Health }\end{array}$ & 2011 \\
\hline 4 & Dullet et al. [4] & $\begin{array}{l}\text { Impact of a University-based Outpatient Telemedicine Program on } \\
\text { Time Savings, Travel Costs, and Environmental Pollutants }\end{array}$ & 2017 \\
\hline 5 & Helsel BC et al. [5] & $\begin{array}{l}\text { Telemedicine and Mobile Health Technology are Effective in the } \\
\text { Management of Digestive Diseases: A Systematic Review }\end{array}$ & 2018 \\
\hline 6 & Strode, Gustke, Allen. [6] & Technical and Clinical Progress in Telemedicine & 1999 \\
\hline 7 & $\emptyset$ stbye \& Hurlen. [7] & $\begin{array}{l}\text { The Electronic House Call: Consequences of Telemedicine Consul- } \\
\text { tations for Physicians, Patients, and Society }\end{array}$ & 1997 \\
\hline 8 & Garshnek, Frederick, Burkle. [8] & $\begin{array}{c}\text { Applications of Telemedicine and Telecommunications to Disaster } \\
\text { Medicine: Historical and Future Perspectives }\end{array}$ & 1999 \\
\hline 9 & Latifi \& Tilley. [11] & $\begin{array}{l}\text { Telemedicine for Disaster Management: Can It Transform Chaos } \\
\text { Into an Organized, Structured Care From the Distance }\end{array}$ & 2014 \\
\hline 10 & Ahmed, Sandhya, Shankar. [15] & $\begin{array}{c}\text { ICT's Role in Building and Understanding Indian Telemedicine } \\
\text { Environment: A Study }\end{array}$ & 2019 \\
\hline 11 & Handschu et al. [17] & $\begin{array}{l}\text { Telemedicine in Emergency Evaluation of Acute Stroke: Inter-rater } \\
\text { Agreement in Remote Video Examination With a Novel Multime- } \\
\text { dia System }\end{array}$ & 2003 \\
\hline 12 & Lambrecht. [18] & Emergency Physicians' Roles in a Clinical Telemedicine Network & 1997 \\
\hline 13 & Czaplik [19] & $\begin{array}{l}\text { Employment of Telemedicine in Emergency Medicine: Methods of } \\
\qquad \text { Information in Medicine }\end{array}$ & 2017 \\
\hline
\end{tabular}

\section{Results}

According to the first phase of the study, 6 key themes with 38 subthemes of applicable telemedicine for implementing in the disaster were obtained. Technical infrastructure with 11 subthemes and financial infrastructure with 4 subthemes had maximum and minimum subthemes, respectively (Table 3 ). In the second phase, all key themes and subthemes are scored by the participants individually. In this phase, social and cultural infrastructure themes obtained the minimum Mean \pm SD score of $\mathrm{Mean} \pm \mathrm{SD}=7.29 \pm 2.07$ and telecommunication infrastructure the maximum Mean \pm SD score of Mean $\pm \mathrm{SD}=8.93 \pm 1.68$ (Table 4).

Table 2. Demographic characteristics of the participated experts

\begin{tabular}{|c|c|c|c|}
\hline & hics & No.(\%) & Total/ No.(\%) \\
\hline \multirow{4}{*}{ SEX } & Male & $31(89 \%)$ & \\
\hline & & & \\
\hline & Female & $4(11 \%)$ & \\
\hline & BS & $6(17 \%)$ & \\
\hline \multirow[t]{4}{*}{ Education Level } & MS & $15(43 \%)$ & \\
\hline & & & $35(100 \%)$ \\
\hline & $\mathrm{PhD}$ & $14(40 \%)$ & \\
\hline & Disaster management & $4(13 \%)$ & \\
\hline \multirow[t]{2}{*}{ Profession } & Medicine & $8(22 \%)$ & \\
\hline & Information technology & $23(65 \%)$ & \\
\hline
\end{tabular}


Table 3. Key themes and subthemes of applicable telemedicine in disaster

\begin{tabular}{|c|c|c|}
\hline Row & Key Themes & Subthemes \\
\hline 1 & \multirow{7}{*}{ Telecommunication infrastructure } & High-speed Internet \\
\hline 2 & & Communication network reliability (system design with plug-in equipment) \\
\hline 3 & & Bandwidth \\
\hline 4 & & The mobile network \\
\hline 5 & & The cable network \\
\hline 6 & & Satellite communication \\
\hline 7 & & Information Exchange Security \\
\hline 8 & \multirow{11}{*}{ Technical infrastructure } & The proper hardware \\
\hline 9 & & The proper software \\
\hline 10 & & Fast system installation \\
\hline 11 & & Possibility to move the system \\
\hline 12 & & User-friendly system \\
\hline 13 & & Compliance with system standards (audio and video transmission, etc.) \\
\hline 14 & & Compliance with information exchange standards \\
\hline 15 & & Providing simultaneous voice calling \\
\hline 16 & & Sustainable energy supply \\
\hline 17 & & Providing simultaneous video calling \\
\hline 18 & & Possibility of large-scale provision \\
\hline 19 & \multirow{6}{*}{ Social and cultural infrastructure } & Acceptance in society (the general public) \\
\hline 20 & & Acceptance and acceptability among service providers \\
\hline 21 & & Special training for servants \\
\hline 22 & & Public education for service recipients \\
\hline 23 & & Satisfaction of service providers \\
\hline 24 & & Satisfaction of recipients \\
\hline 25 & \multirow{5}{*}{ Health infrastructure } & Access to medical records and health of individuals \\
\hline 26 & & Observing the principles of medical ethics \\
\hline 27 & & Ability to communicate with specialized health center \\
\hline 28 & & Ability to communicate with the disaster affected area \\
\hline 29 & & Communication with CDC (Center for Disease Control and Prevention) \\
\hline 30 & \multirow{4}{*}{ Financial infrastructure } & Initial investment \\
\hline 31 & & Concurrent costs \\
\hline 32 & & Cost-effective service delivery \\
\hline 33 & & Fee for service providers \\
\hline 34 & \multirow{5}{*}{ Organizational infrastructure } & Legal considerations (definition of the law and instructions) \\
\hline 35 & & HTML Editor and Style Sheets \\
\hline 36 & & Compilation of the organizational chart of the operation process \\
\hline 37 & & Support for policy makers and managers \\
\hline 38 & & Ability to integrate matters into crisis response \\
\hline
\end{tabular}


Table 4. Descriptive statistics of key elements in the second stage

\begin{tabular}{ccccccc}
\hline Statistics & $\begin{array}{c}\text { Telecommunication } \\
\text { Infrastructure }\end{array}$ & $\begin{array}{c}\text { Technical } \\
\text { Infrastructure }\end{array}$ & $\begin{array}{c}\text { Financial } \\
\text { Infrastructure }\end{array}$ & $\begin{array}{c}\text { Health } \\
\text { Infrastructure }\end{array}$ & $\begin{array}{c}\text { Organizational } \\
\text { Infrastructure }\end{array}$ & $\begin{array}{c}\text { Social and Cultural } \\
\text { Infrastructure }\end{array}$ \\
\hline Mean & 8.93 & 8.89 & 8.64 & 7.89 & 7.61 & 7.29 \\
Median & 10 & 9 & 9 & 8 & 7.5 & 7 \\
Mode & 10 & 10 & 10 & 8 & 9 & 1.87 \\
\hline $\begin{array}{c}\text { Standard } \\
\text { deviation }\end{array}$ & 1.68 & 1.03 & 1.45 & 1.45 & 2.07 \\
\hline
\end{tabular}

In this phase, 5 subthemes were removed from the criteria because they obtained scores less than expectation. The "cable network" subtheme from telecommunication infrastructure theme, "acceptance in society" (the general public) and "public education for service recipients" subthemes from social and cultural infrastructure theme, the "cost-effective service delivery" and "fee for service providers" subthemes from financial infrastructure theme were removed from the criteria.

In the third phase, validation of the model was performed after rearranging subthemes. In this phase, the remaining 28 participated experts scored key themes and subthemes. Then, the highest priority went to telecommunication infrastructure with a maximum score of 9.24 and least priority to social and cultural infrastructure theme with a minimum score of 7.53 (Table 5).

According to the scores of themes and their subthemes, the final model was created with 6 key themes and 35 subthemes (Table 6).

In the final model, 2 subthemes obtained maximum scores, i.e. the communication network reliability of the telecommunication infrastructure theme and the initial investment of the financial infrastructure theme. The satisfaction of recipients' subtheme of the social and cultural infrastructure theme with the least score of 6.86 was placed in the bottom.

\section{Discussion}

In this study, we tried to create an applicable model of telemedicine in disasters for Iran, with the focus on earthquake. Given that earthquake is one of the most important natural disasters in our country, and about 93\% of Iran are at risk of the earthquake [11], we need new technologies such as telemedicine to provide health services in the affected areas. Because of the rapid development of telecommunication industry in Iran with the improvement of communication all over the country, there is a good chance for using telemedicine [12].

There are many successful implementations of remote health services in the world from the beginning of their usage since the mid-1980s. Past experiences allow scientists to extrapolate how telemedicine will evolve to meet future needs in disasters [8]. From the first usage of telecommunication technology in Mexico City earthquake in 1985 to remote surgery in recent years, telemedicine has developed unbelievably. In recent years with the development of cellular phones, counseling and medical

Table 5. Results of prioritizing the key themes of applicable telemedicine in earthquake

\begin{tabular}{|c|c|c|}
\hline Key Theme & Score & Rank \\
\hline Telecommunication infrastructure & 9.24 & 1 \\
\hline Technical infrastructure & 9.22 & 2 \\
\hline Financial infrastructure & 8.98 & 3 \\
\hline Health infrastructure & 8.19 & 4 \\
\hline Organizational infrastructure & 7.87 & 5 \\
\hline Social and cultural infrastructure & 7.53 & 6 \\
\hline
\end{tabular}


Table 6. Ranked key themes and subthemes of applicable telemedicine in earthquake

\begin{tabular}{|c|c|c|c|c|c|c|}
\hline & Key Theme & Subtheme & Mean & Median & Mode & SD \\
\hline 1 & \multirow{6}{*}{$\begin{array}{l}\text { Telecommunication } \\
\text { Infrastructure }\end{array}$} & Communication network reliability & 8.93 & 10 & 10 & 1.33 \\
\hline 2 & & Satellite communication & 8.75 & 9 & 8 & 1.21 \\
\hline 3 & & Bandwidth & 8.39 & 8.5 & 10 & 1.61 \\
\hline 4 & & Mobile network & 8.04 & 8 & 8 & 1.75 \\
\hline 5 & & High-speed Internet & 7.61 & 8.5 & 10 & 2.68 \\
\hline 6 & & Information Exchange Security & 7.32 & 8 & 10 & 2.21 \\
\hline 7 & \multirow{11}{*}{$\begin{array}{c}\text { Technical } \\
\text { infrastructure }\end{array}$} & The proper software & 8.71 & 9 & 10 & 1.21 \\
\hline 8 & & The proper hardware & 8.68 & 9 & 9 & 1.19 \\
\hline 9 & & Fast system installation & 8.57 & 9.5 & 10 & 1.97 \\
\hline 10 & & User-friendly system & 8.57 & 9 & 10 & 1.55 \\
\hline 11 & & Sustainable energy supply & 8.57 & 9 & 10 & 1.67 \\
\hline 12 & & Possibility to move the system & 8.46 & 9 & 10 & 1.91 \\
\hline 13 & & Providing simultaneous voice calling & 8.04 & 8 & 10 & 1.55 \\
\hline 14 & & Providing simultaneous video calling & 7.68 & 7 & 7 & 1.91 \\
\hline 15 & & Compliance with information exchange standards & 7.29 & 8 & 8 & 1.94 \\
\hline 16 & & $\begin{array}{l}\text { Compliance with system standards (audio and video transmis- } \\
\text { sion, etc.) }\end{array}$ & 7.14 & 7 & 7 & 1.96 \\
\hline 17 & & Possibility of large-scale provision & 6.96 & 7.5 & 9 & 2.41 \\
\hline 18 & \multirow{2}{*}{$\begin{array}{c}\text { Financial } \\
\text { infrastructure }\end{array}$} & Initial investment & 8.93 & 9.5 & 10 & 1.30 \\
\hline 19 & & Concurrent costs & 7.68 & 8 & 9 & 1.87 \\
\hline 20 & \multirow{5}{*}{ Health infrastructure } & Access to medical and health records of individuals & 7.11 & 8 & 8 & 2.23 \\
\hline 21 & & Observing the principles of medical ethics & 8 & 8 & 10 & 1.98 \\
\hline 22 & & Ability to communicate with specialized health centers & 8.14 & 8 & 8 & 1.60 \\
\hline 23 & & $\begin{array}{l}\text { Ability to communicate with the crisis management area of the } \\
\text { region }\end{array}$ & 8.75 & 9.5 & 10 & 1.38 \\
\hline 24 & & $\begin{array}{l}\text { Communication with CDC (Center for Disease Control and } \\
\text { Prevention) }\end{array}$ & 7.75 & 8 & 10 & 1.65 \\
\hline 25 & \multirow{5}{*}{$\begin{array}{l}\text { Organizational } \\
\text { infrastructure }\end{array}$} & Legal considerations (definition of law and instructions) & 8.07 & 8 & 10 & 1.80 \\
\hline 26 & & HTML Editor and Style Sheets & 8.61 & 9.5 & 10 & 1.77 \\
\hline 27 & & $\begin{array}{l}\text { Compilation of the organizational chart of the operation process } \\
\text { (activation of the system) }\end{array}$ & 8.21 & 9 & 10 & 1.77 \\
\hline 28 & & Support for policymakers and managers & 8.75 & 9 & 9 & 1 \\
\hline 29 & & Ability to integrate matters into crisis response & 8.14 & 8 & 8 & 1.41 \\
\hline 30 & \multirow{4}{*}{$\begin{array}{l}\text { Social and cultural } \\
\text { infrastructure }\end{array}$} & Acceptance and acceptability among service providers & 7.29 & 7 & 6 & 1.84 \\
\hline 31 & & Special training for servants & 8.32 & 9 & 10 & 2.11 \\
\hline 32 & & Satisfaction of service providers & 7.39 & 8 & 8 & 1.64 \\
\hline 33 & & Satisfaction of recipients & 6.86 & 7 & 8 & 1.96 \\
\hline
\end{tabular}


diagnostic interventions are available. Surgeons can do complicated operations with the help of reliable communication technology, such as long-term evolution [13].

In our study, the experts categorized key elements of a telemedicine application in 6 themes. Our study results indicated that having the appropriate telecommunication tools along with financing for the proper maintenance of the equipment is very important. The importance of these cases in other studies shows clearly the telemedicine conceptual framework. Innovation in Information and Communication Technology (ICT) with considerable investments in the field of healthcare informatics, resulted in improving and extending medical services in remote, unprivileged areas with important social and economic benefits [14].

To implement telemedicine in Iran, it is first necessary to identify the principle and partner organizations with a clear task description. Then the essential infrastructure should be developed according to specific goals. The most important infrastructures are the technical and telecommunication infrastructure (including telemedicine equipment, strong and efficient communications and the development of platforms, increased bandwidth and access to intranets and the Internet), social and cultural infrastructure (public education, special education for users, specialist physicians, medical and paramedical students and emergency aid staff), security infrastructure (coordination with network police, security information centers and electronic signatures), legal considerations (legal guidelines, rules and regulations related to health) and standardization infrastructure (information exchange standards, vocabulary, security, and system architecture).

Other studies also emphasized these obstacles in the implementation of telemedicine due to specific environments. In one study in India declared the role of ICT and the context of Indian society for implementing telemedicine. They noted the importance of telecommunication infrastructure along with economic and sociocultural infrastructure [15].

The vulnerability assessment of the equipment and facilities of the telemedicine infrastructure is very important. Reliable and persistent communication along with well-established devices in both side of telemedicine technology is mandatory. There are many automated solutions to help us control our telemedicine environment better [16].

\section{Conclusion}

In this research, due to the nature of the future and the novelty of the subject, the Delphi method was used to identify the key themes and subthemes of telemedicine implementation in Iran during an earthquake disaster. We believe that our model of telemedicine implementation is an appropriate model for Iran. We suggest that the results of this study be implemented as a theoretical model, or in the pilot study, in a region of the country. Then, the outcomes are investigated regarding the amount of mortality reduction. We also recommend that a comparative study is done for using telemedicine in other types of disasters.

\section{Ethical Considerations}

\section{Compliance with ethical guidelines}

There was no ethical considerations to be considered in this research

\section{Funding}

This research did not receive any specific grant from funding agencies in the public, commercial, or not-forprofit sectors. Farhad Fatehi received financial support from the Queensland Government through an Advance Queensland Research Fellowship.

\section{Authors' contributions}

All authors contributed in preparing this article.

Conflict of interest

The authors declared no conflict of interest.

Acknowledgments

The present paper has been extracted from a part of Master's dissertation of the first author at Faculty of Medical Engineering, Amirkabir University of Technology.

\section{References}

[1] Bashshur RL, Shannon GW, Sanders JH. Telemedicine: Theory and practice. Springfield: Charles C. Thomas; 1997.

[2] Crane PW, Wiegand TJ, Kamali M, Reif M, Wratni R, Montante R, et al. Telemedicine Delivery and Successful Reimbursement in Toxicology. Journal of Medical Toxicology. 
2018; 14(3):242-7. [DOI:10.1007/s13181-018-0665-5] [PMID] [PMCID]

[3] Nicogossian AE, Doarn CR. Armenia 1988 earthquake and telemedicine: lessons learned and forgotten. Telemedicine and e-Health. 2011; 17(9):741-5. [DOI:10.1089/tmj.2011.0118] [PMID]

[4] Dullet NW, Geraghty EM, Kaufman T, Kissee JL, King J, Dharmar M, et al. Impact of a university-based outpatient telemedicine program on time savings, travel costs, and environmental pollutants. Value in Health. 2017; 20(4):542-6. [DOI:10.1016/j.jval.2017.01.014] [PMID]

[5] Helsel BC, Williams JE, Lawson K, Liang J, Markowitz J. Telemedicine and mobile health technology are effective in the management of digestive diseases: A systematic review. Digestive Diseases and Sciences. 2018; 63(6):1392-408 [DOI:10.1007/s10620-018-5054-z] [PMID]

[6] Strode SW, GustkeS, Allen A. Technical and clinical progress in telemedicine. Jama. 1999; 281(12):1066-8. [DOI:10.1001/ jama.281.12.1066] [PMID]

[7] Østbye T, Hurlen P. The electronic house call: consequences of telemedicine consultations for physicians, patients, and society. Archives of Family Medicine. 1997; 6(3):266-77. [DOI:10.1001/archfami.6.3.266] [PMID]

[8] Garshnek V, Burkle FM. Applications of telemedicine and telecommunications to disaster medicine: Historical and future perspectives. Journal of the American Medical Informatics Association. 1999; 6(1):26-37. [DOI:10.1136/jamia.1999.0060026] [PMID] [PMCID]

[9] International Institute of Earthquake Engineering and Seismology. Preliminary Earthquake Reconnaissance Report on the June 22, 2002 Changureh (Avaj), Iran Earthquake. [Internet]. 2002 [Updated 2010 March 25] Availabe from http:/ / www.iiees.ac.ir/en/ preliminary-report-of-iiees-reconnaissance-team-the-changureh-avaj-earthquake-of-june22-2002-mw64/

[10] Ghomian Z, Yousefian S. Natural Disasters in the MiddleEast and North Africa With a Focus on Iran: 1900 to 2015. HDQ. 2017; 2(2):53-62. [DOI:10.18869/nrip.hdq.2.2.53]

[11] Latifi R, Tilley EH. Telemedicine for disaster management: can it transform chaos into an organized, structured care from the distance. American Journal of Disaster Medicine. 2014 9(1):25-37. [DOI:10.5055/ajdm.2014.0139] [PMID]

[12] Nekoueizadeh S, Esmaeili S. A study of the impact of TQM on organizational performance of the telecommunication Industry in Iran. European Online Journal of Natural and Social Sciences. 2013; 2(3):968-78.

[13] Lynn M. Telemedicine to manage sudden Mass casualty incidents remotely. In: Lynn M, Lieberman H, Lynn L, Pust GD, Stahl K, Yeh DD, et al. editors. Disasters and Mass Casualty Incidents. Cham: Springer; 2019. [DOI:10.1007/978-3319-97361-6_17]

[14] Vizitiu C. TeleMedicine-theoretical framework. In: Vizitiu C, editor. Systems Engineering and Organizational Assessment Solutions Ensuring Sustainability within Telemedicine Context. Wiesbaden: Springer Gabler; 2019. [DOI:10.1007/978-3-658-23538-3_4]

[15] Ahmed SS, Sandhya M, Shankar S. ICT's role in building and understanding indian telemedicine environment: A study. In: Fong S, Akashe S, Mahalle P, editors. Information and Communication Technology for Competitive Strategies. Downtown Core: Springer; 2019. [DOI:10.1007/978-981-130586-3_39]

[16] Nikoloudakis Y, Pallis E, Mastorakis G, Mavromoustakis CX, Skianis C, Markakis EK. Vulnerability assessment as a service for fog-centric ICT ecosystems: A healthcare use case. Peer-to-Peer Networking and Applications. 2019; 2019:1-9. [DOI:10.1007/s12083-019-0716-y]

[17] Handschu R, Littmann R, Reulbach U, Gaul C, Heckmann JG, Neundörfer B, et al. Telemedicine in emergency evaluation of acute stroke: Interrater agreement in remote video examination with a novel multimedia system. Stroke. 2004; 34(12):2842-6. [DOI:10.1161/01.STR.0000102043.70312.E9] [PMID]

[18] Lambrecht CJ. Emergency physicians' roles in a clinical telemedicine network. Annals of emergency medicine. 1997; 30(5):670-4. [DOI:10.1016/S0196-0644(97)70087-8]

[19] Czaplik M, Bergrath S, Rossaint R, Thelen S, Brodziak T, Valentin B, et al. Employment of telemedicine in emergency medicine. clinical requirement analysis, system development and first-test results. Methods of Information in Medicine. 2014; 53(2):99-107. [DOI:10.3414/ME13-01-0022] [PMID] 